\title{
I've sold my sport-utility vehicle
}

\author{
Stephen B Hanauer
}

I am writing this editorial as the US awaits the brunt of hurricane Wilma after already experiencing the dramatic effects of hurricanes Katrina and Rita on the Gulf coast (Gulf of Mexico). The fact that 2005 has already been the most prolific year for Atlantic hurricanes might be directly attributable to global warming. In addition to the immediate impact of global warming on the incidence and severity of storms, floods, droughts and heat waves, we can expect the changing environment to have unanticipated effects on human health. Indeed, in the October 6 issue of the New England Journal of Medicine Paul Epstein, Associate Director of the Center for Health and the Global Environment at Harvard Medical School, provides a perspective on Climate Change and Human Health. ${ }^{1}$ Notable impacts of global warming on human health include the increasing prevalence of asthma and mosquitoborne illnesses, as well as diseases spread by microbial vectors.

An immediate and unexpected consequence of global warming was exposed in the same issue of the New England Journal of Medicine, reported as An Outbreak of Vibrio parahaemolyticus Gastroenteritis Associated with Alaskan Oysters, by McLaughlin et al. ${ }^{2}$ The series is not unusual for the epidemic of gastroenteritis that was reported, but, instead, for the infectious cause. As the authors point out, seafood-associated gastroenteritis "...typically is associated with the consumption of raw oysters gathered from warm-water estuaries." What makes this outbreak unusual is that the implicated oysters were harvested from an Alaskan farm that is $1,000 \mathrm{~km}$ north of the previously northernmost documented source of oyster-induced V. parahaemolyticus illness. Furthermore, the investigators were able to document the water temperatures at the implicated farm and found that the oysters were harvested when the mean

\section{...we can \\ expect the \\ changing \\ environment \\ to have \\ unanticipated \\ effects on \\ human health}

SB Hanauer is Editorin-Chief of Nature Clinical Practice Gastroenterology \& Hepatology.

\section{Competing interests}

The author declared he has no competing interests.

www.nature.com/clinicalpractice doi:10.1038/ncpgasthep0361 daily water temperatures exceeded $15.0^{\circ} \mathrm{C}$. It was found that the mean water temperature of the farm in Prince William Sound (Gulf of Alaska) had risen by $0.21^{\circ} \mathrm{C}$ per year since 1997 , and the summer of the outbreak was the first year that the mean daily water temperature had not dropped below $15.0^{\circ} \mathrm{C}$. While changing water temperatures alone might not account for this particular outbreak, other potential causes, such as changes in animal migration, might also relate to changes in the global climate.

Gastroenterologists and other health-care providers worldwide need to be aware of these potential new sources of illness. Indeed, the index case for the $V$. parahaemolyticus outbreak was identified by a health official in Nevada! The Alaska Department of Environmental Conservation was alerted to the problem by the health official and they notified the Alaska Section of Epidemiology, who worked with the Alaska Division of Public Health and the Centers for Disease Control and Prevention to contain the outbreak. Quite a distance from Nevada to Anchorage to Atlanta!

Ultimately, it is highly suspected that this unexpected disease outbreak is another signal of the impact that global warming is having and, as Paul Epstein points out, “....we may be underestimating the breadth of biologic responses to changes in climate. Treating climate-related ills will require preparation, and early-warning ... to reduce casualties and curtail the spread of disease."

With the ever-increasing cost of oil we now have additional incentives to consider the environmental impact of our lifestyle and energy policies.

Supplementary information, in the form of a reference list, is available on the Nature Clinical Practice Gastroenterology \& Hepatology website. 